\title{
Toughness Characterization of Fiber Reinforced Concrete Beam using Fracture Mechanics
}

\author{
Kiran Malipatil, Varunashree Meti, Siddramappa Itti
}

\begin{abstract}
The study of fracture mechanics was very much essential because it gives clear idea of arising and propagation of cracks, cause for failure, life of structure, etc. The main aim of this research was to study the fracture behavior of fiber reinforced concrete which was reinforced with polypropylene fiber. The fiber used in concrete with different volume fraction like $0.5 \%, 0.75 \%$ and $1 \%$ of total volume of cementitious material. The specimens were prepared with different grades of concrete with different dosage of fiber and then subjected to three point bending test. Using test results the fracture properties like fracture energy, flexural strength; stress intensity factor, fracture toughness and stiffness were found. The experimental results showed that effectiveness of polypropylene fiber for different grades of concrete that is normal, medium and high strength concrete increases with increase in fiber volume and also the fracture properties of fiber reinforced concrete increases with increase in fiber volume and effectiveness of fiber was found for dosage of about $0.75-1 \%$ volume.
\end{abstract}

Keywords: Fracture mechanics, fracture property; effectiveness of fiber, polypropylene fiber, Stress Intensity factor

\section{INTRODUCTION}

$\mathrm{F}_{\text {racture mechanics was a branch of mechanics which }}$ mainly deals with spread of cracks in the materials. Thus helped to analyze characteristics of material and material resistance to fracture. When the concept of structure comes into mind, one has to concentrate on importance of material required to build strong structure. Since from $21^{\text {st }}$ century concrete has become popular construction material because of its low cost and easy availability of raw materials. As we knew that concrete is weak in tension because of which it shows some brittle behavior and undergoes failure easily, so it was important to study facture mechanics of concrete.

Every material has got different lifespan likewise concrete also had some life span. The failure of material would be either in the form of fracture or in the form of cracks, break, etc. This would be reduced to some extent using different materials like fibers, steel reinforcement in the plain mix which will not completely reduce the failure but increases life span. One such material considered in the research work was fibers to analyze the fracture properties of different concrete.

Revised Manuscript Received on February 05, 2020.

* Correspondence Author

Kiran M. Malipatil*, Assistant Professor, Department of Civil Engineering, KLE DRMSSCET Belagavi, Karnataka, India

Varunashree Meti, (MTech.), Structural engineering, Belagavi, Karnataka, India.

Dr S.V. Itti, Professor Department of Civil Engineering, SGBIT, Belagavi, Karnataka

(C) The Authors. Published by Blue Eyes Intelligence Engineering and Sciences Publication (BEIESP). This is an open access article under the CC BY-NC-ND license (http://creativecommons.org/licenses/by-nc-nd/4.0/)
Fibers were thin thread like materials whose length is found to be more than width. Later fibers categorized as natural fibers like jute, hemp, etc. and artificial fibers like polypropylene fiber, steel fibers, carbon fibers, etc.

In the present study the artificial fibers decided to use was polypropylene fiber. Polypropylene fibers were manmade fiber which comes under category of polymer fiber which has better durability and thermal resistance property. These

fibers were mainly preferred because addition of these fibers reduces internal forces by blocking of microscopic cracks within concrete. The modulus of elasticity of this fiber was around 3.5-4.3GPa and ultimate elongation was found to be 15\%. [1, 2, 3, 5]

Polypropylene fiber available in variety shapes and types in market like plain, buttoned ends, fibrillated, twisted type, etc. The main disadvantage of fiber reinforced concrete was difficult in fabrication and cost needed is more compared to plain concrete. [9]

\section{METHODOLOGY}

To achieve objectives of research work proper methodology has to be set. And this includes materials, mix design, casting, curing and testing of specimens. The materials include ordinary Portland cement, fine aggregate (FA), coarse aggregate (CA), polypropylene fiber, super plasticizer, silica fume, fly ash and water. The fiber used was monofilament form confirming to IRC: SP: 46-2013, ASTMC 1116, having length around $6 \mathrm{~mm}$ and diameter of 15microns (Fig.1).The tensile property of fiber was around 600GPa, aspect ratio was 600 and specific gravity was 0.91 . The physical properties of concrete shown in table 1 below.

The mix design for different grades of concrete like $\mathrm{M}_{20}$, $\mathrm{M}_{40}$, and $\mathrm{M}_{60}$ were done as per IS: 10262-2019. Water cement ratio was maintained about $0.55,0.4$ and 0.3 .The FA aggregate used was zone 2 and CA of size $20 \mathrm{~mm}$. The chemical admixture added upto dosage of $2 \%$ and $0.5 \%$ of total cementitious material for $\mathrm{M}_{40}$, and $\mathrm{M}_{60}$ (Table 2).

Two beam specimens were prepared having size of about 150x100x600mm(S 1) and 150x200x1200mm(S 2) with U-notch of size $6 \times 16.66 \mathrm{~mm}$ for $600 \mathrm{~mm}$ span specimen and $6 \times 33.3 \mathrm{~mm}$ for $1200 \mathrm{~mm}$ span specimen(fig. 2\& 3). The dosage of fiber was maintained about $0.5 \%, 0.75 \%$ and $1 \%$ [11] of total cementitious material. Total specimens casted were 54 i.e., 18 specimens for each mix. [15] 


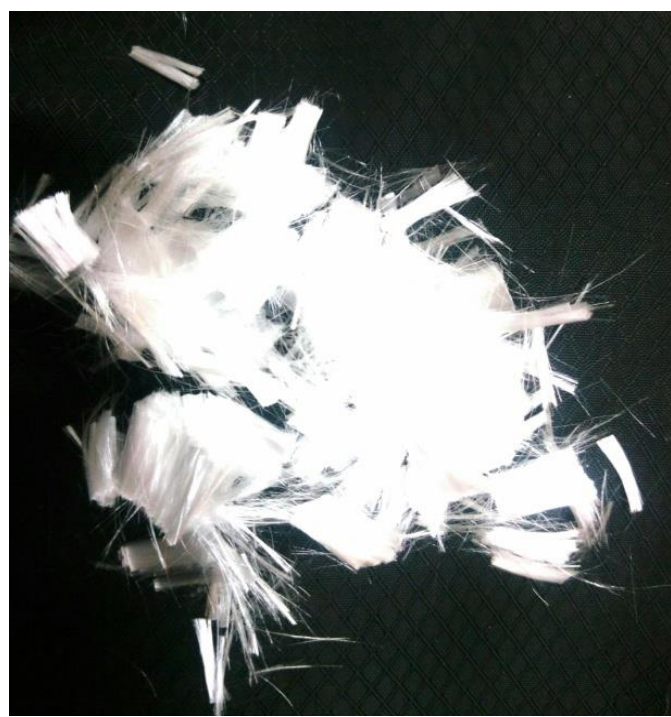

Fig.1. Polypropylene fiber (monofilament form)

Table- I: Physical Properties Of Fiber

\begin{tabular}{|c|c|}
\hline Specific gravity & 0.91 \\
\hline Melt point $\left({ }^{\circ} \mathrm{c}\right)$ & 165 \\
\hline Acid and alkali resistance & Excellent \\
\hline Aspect ratio & 400 \\
\hline Tensile strength(GPa) & 660 \\
\hline
\end{tabular}

Table- II Mixture proportitions of different grade concrete

\begin{tabular}{|c|c|c|c|c|}
\hline \multicolumn{2}{|c|}{ Materials used } & $\mathbf{M}_{20}$ & $\mathbf{M}_{40}$ & $\mathbf{M}_{60}$ \\
\hline \multicolumn{2}{|c|}{ Cement $\left(\mathrm{kg} / \mathrm{m}^{3}\right)$} & 338 & 350 & 368 \\
\hline \multicolumn{2}{|c|}{$\begin{array}{l}\text { Coarse aggregate } \\
\left(\mathrm{kg} / \mathrm{m}^{3}\right)\end{array}$} & 1099.5 & 1144.6 & 1259 \\
\hline \multicolumn{2}{|c|}{ Fine aggregate $\left(\mathrm{kg} / \mathrm{m}^{3}\right)$} & 861.8 & 899.4 & 812 \\
\hline \multicolumn{2}{|c|}{ Super plasticizer $\left(\mathrm{kg} / \mathrm{m}^{3}\right)$} & - & 3.5 & 2.3 \\
\hline \multicolumn{2}{|c|}{ Silica fume $\left(\mathrm{kg} / \mathrm{m}^{3}\right)$} & - & - & 69 \\
\hline \multicolumn{2}{|c|}{ Fly ash $\left(\mathrm{kg} / \mathrm{m}^{3}\right)$} & - & - & 23 \\
\hline \multicolumn{2}{|c|}{$\mathrm{W} / \mathrm{C}$ ratio } & 0.55 & 0.4 & 0.33 \\
\hline \multirow{3}{*}{$\begin{array}{l}\text { Fiber } \\
\left(\mathrm{kg} / \mathrm{m}^{3}\right)\end{array}$} & $0.5 \%$ & 1.69 & 1.75 & 2.3 \\
\hline & $0.75 \%$ & 2.54 & 2.63 & 3.45 \\
\hline & $1 \%$ & 3.38 & 3.5 & 4.6 \\
\hline
\end{tabular}

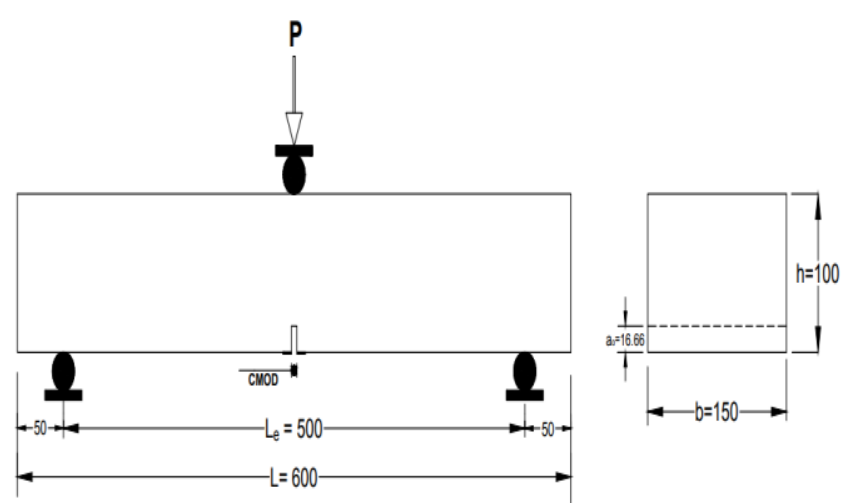

Fig.2. Specimen 1(S 1) of size 150x100x600mm

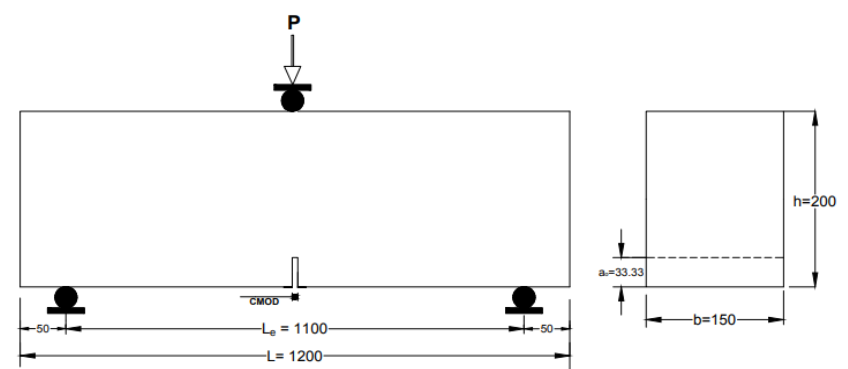

Fig.3. Specimen 2(S 2) of size 150x200x1200mm

\section{TESTING OF THE SPECIMENS}

The specimens were cured for duration of 28days. They were subjected to three-point bending test under UTM machine of $1000 \mathrm{kN}$ capacity to know its strength under different loading condition and to get required properties needed in research work. Using the values of load and respective deflection the fracture energy, flexural strength and stiffness of specimens were calculated. [15]

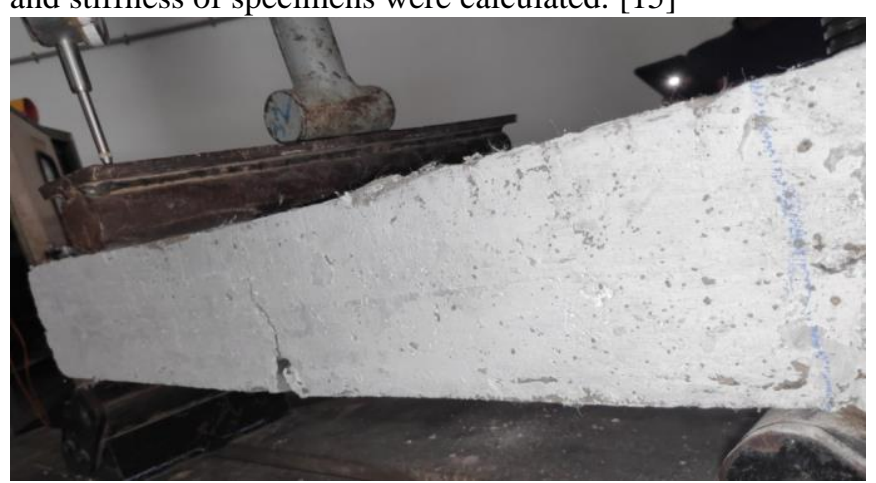

Fig.4. Testing of specimen under UTM

\section{EXPERIMENTAL RESULTS AND ANALYSIS}

\section{A. Calculation of fracture energy}

Fracture energy is nothing but ability of any material to resist fracture. Every material has got some energy to resist or overcome fracture. There were several models like Hillerborg model, Jenq and Shah model, etc. were introduced to calculate fracture energy of FRC specimen. Fracture energy was obtained by considering load-deflection curve where area under curve was divided total area of crack ligament. In present study the fracture energy of FRC beams were calculated using following formula obtained from Hillerborg model [7, 14] -

$\mathrm{G}_{\mathrm{F}}=\frac{\mathrm{Ao}}{\mathrm{b}(\mathrm{d}-\mathrm{ao})}$

Where, $\mathrm{G}_{\mathrm{F}}=$ Fracture energy, $\mathrm{A}_{0}=$ Area under load-deflection curve, $b=$ Width of the beam, $d=$ depth of the beam, $\mathrm{a}_{\mathrm{o}}=$ Depth of the notch

Firstly the formula was mainly introduced for plain concrete but then it was extended for FRC. The specimen tested under three point bending test and using respective load and deflection values the graphs were plotted from which area under curve was calculated and required fracture energy was found. (Table No. 3 and 4) [6, 8]. 

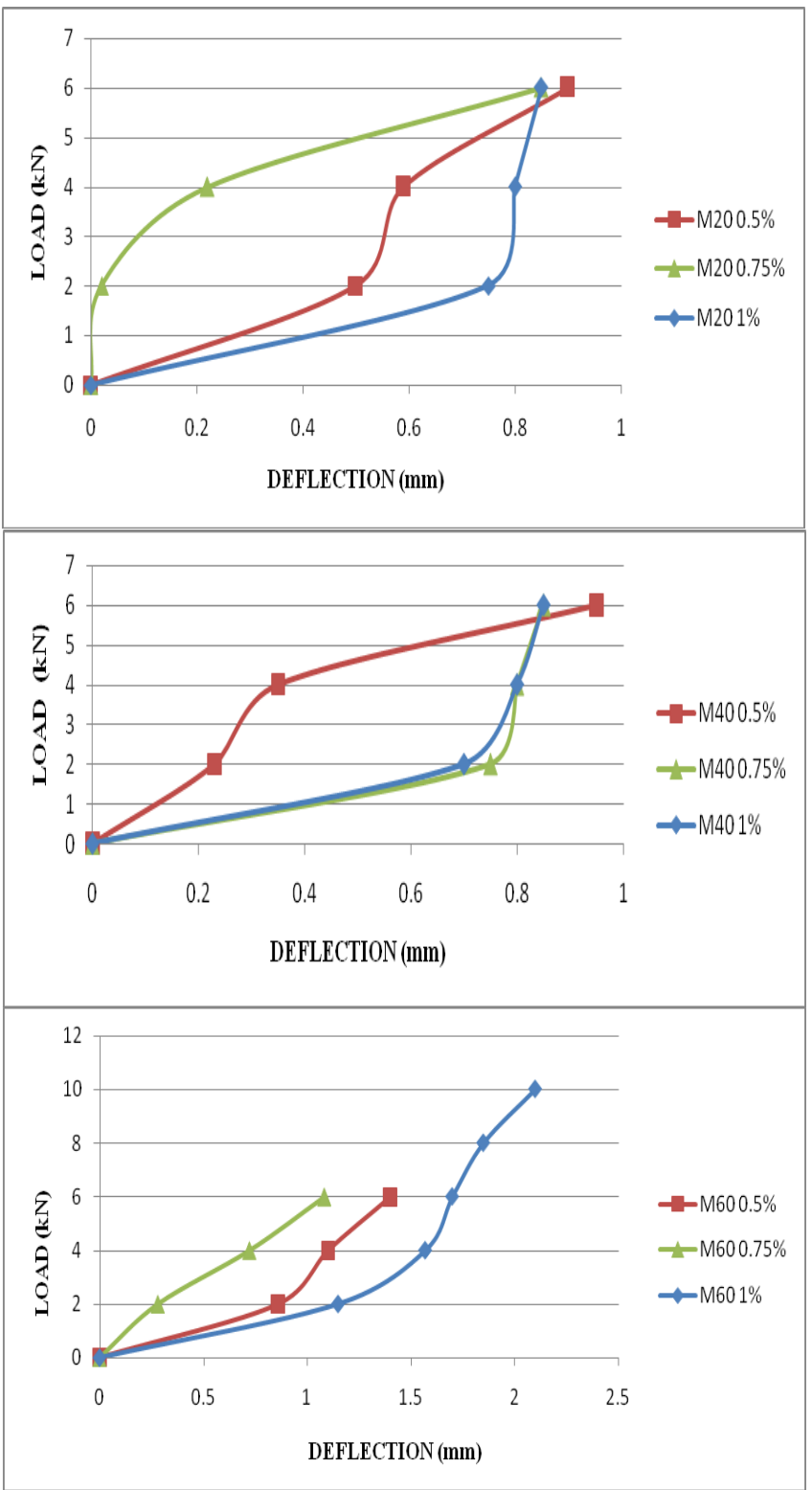

Fig.5. Peak load v/s deflection curve for 150x100x600mm specimen

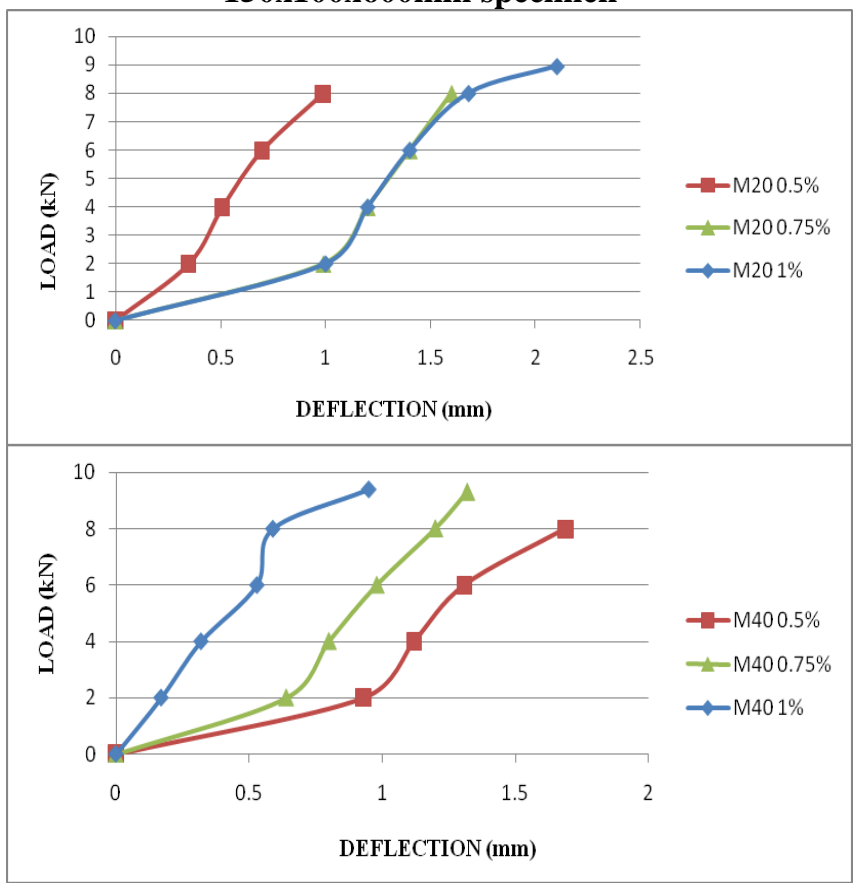

Retrieval Number: C5627029320/2020@BEIESP

DOI: 10.35940/ijeat.C5627.029320

Journal Website: www.ijeat.org

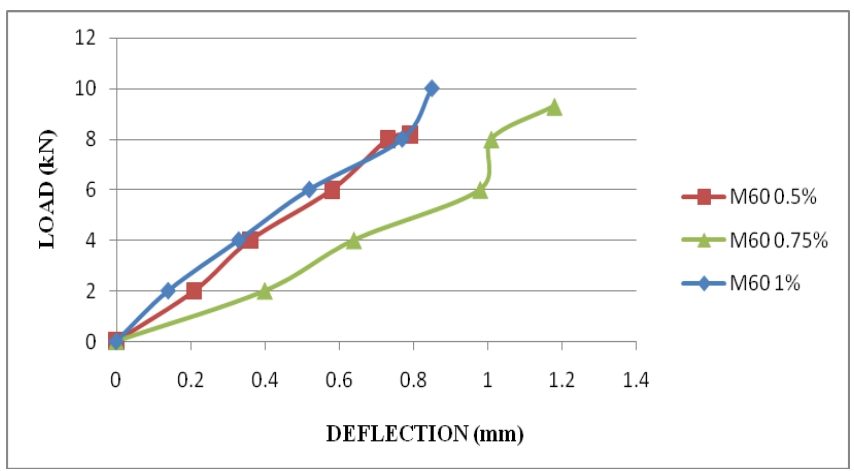

Fig.6. Peak load v/s deflection curve for 150x200x1200mm specimen

Table III Fracture energy at peak load for $1^{\text {st }}$ specimen $(150 \times 100 \times 600 \mathrm{~mm})$

\begin{tabular}{|c|l|l|l|l|}
\hline S 1 & $\begin{array}{c}\text { Fiber Volume } \\
\text { (\%) }\end{array}$ & \multicolumn{3}{|c|}{$\mathbf{G}_{\mathbf{F}}$ (N/mm) } \\
\hline & & $\mathbf{M}_{\mathbf{2 0}}$ & $\mathbf{M}_{\mathbf{4 0}}$ & $\mathbf{M}_{\mathbf{6 0}}$ \\
\hline 600mm span & $0.50 \%$ & 0.24 & 0.35 & 0.35 \\
\hline & $0.75 \%$ & 0.27 & 0.4 & 0.43 \\
\hline & $1 \%$ & 0.27 & 0.41 & 0.71 \\
\hline
\end{tabular}

Table IV Fracture energy at peak load for $2^{\text {nd }}$ specimen (150x200x1200mm)

\begin{tabular}{|c|c|c|c|c|}
\hline S 2 & $\begin{array}{c}\text { Fiber Volume } \\
\text { (\%) }\end{array}$ & \multicolumn{3}{|c|}{$\mathbf{G}_{\mathrm{F}}$ (N/mm) } \\
\hline & & $\mathbf{M}_{\mathbf{2 0}}$ & $\mathbf{M}_{\mathbf{4 0}}$ & $\mathbf{M}_{\mathbf{6 0}}$ \\
\hline $1200 \mathrm{~mm}$ span & $0.50 \%$ & 0.27 & 0.28 & 0.28 \\
\hline & $0.75 \%$ & 0.32 & 0.32 & 0.42 \\
\hline & $1 \%$ & 0.33 & 0.40 & 0.43 \\
\hline
\end{tabular}

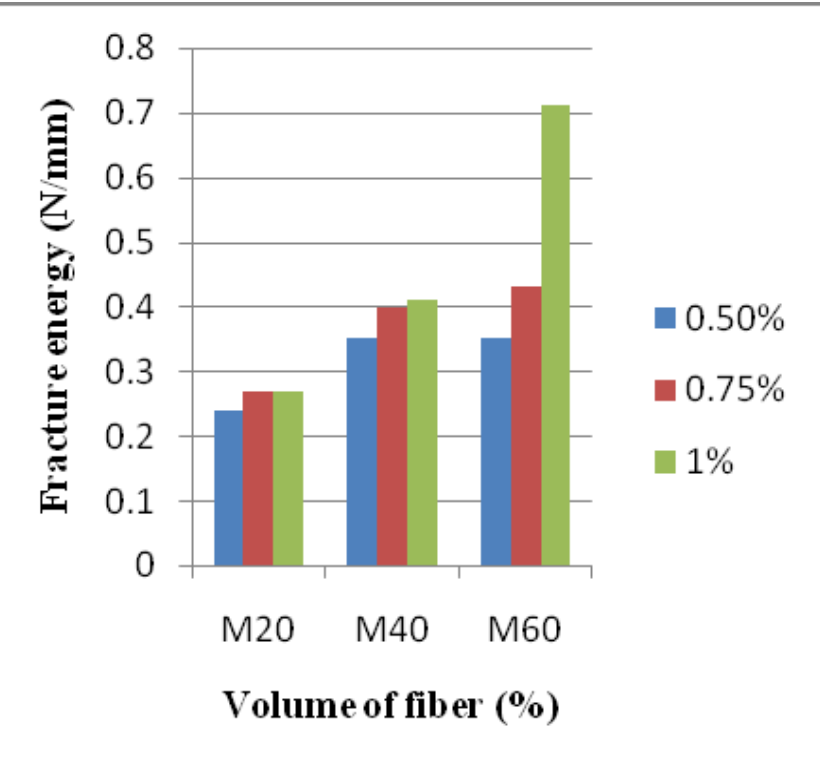

(a) GF for S1

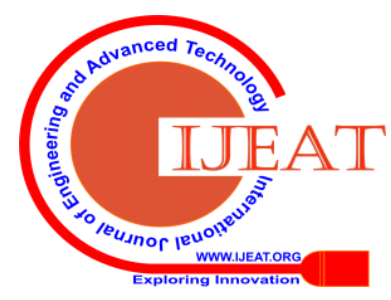




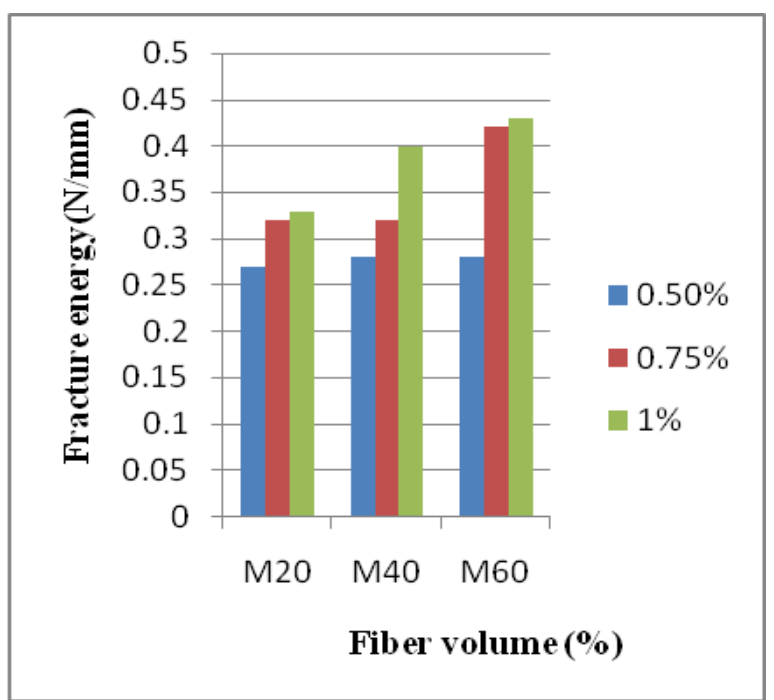

(b) GF for S2

Fig.7. Comparison of fracture energy of different grades of concrete with varying fiber volume [fig. (a) and (b)]

By using load-deflection curve (Fig. 5\& 6) and as per equation 1 the fracture energy of different grades of concrete was calculated. Further these results were compared with different volume of fiber with different grades of concrete to know the influence of fiber on fracture energy. Fig. 7 gives comparison of fracture energy of different grades of concrete with different dosage of polypropylene fiber for both specimens.

\section{B. Flexure Strength}

Flexure strength was material property where amount of stress in the material before it undergoes failure or yielding during testing. The computation of flexure strength was done to get idea regarding how exactly the specimen or beam bends before yielding. Fig. 8 given below illustrates flexural strength of both FRC beam specimens with varying dosage of fiber. Further these results were compared to know the application of fiber to flexural strength. $[4,10]$

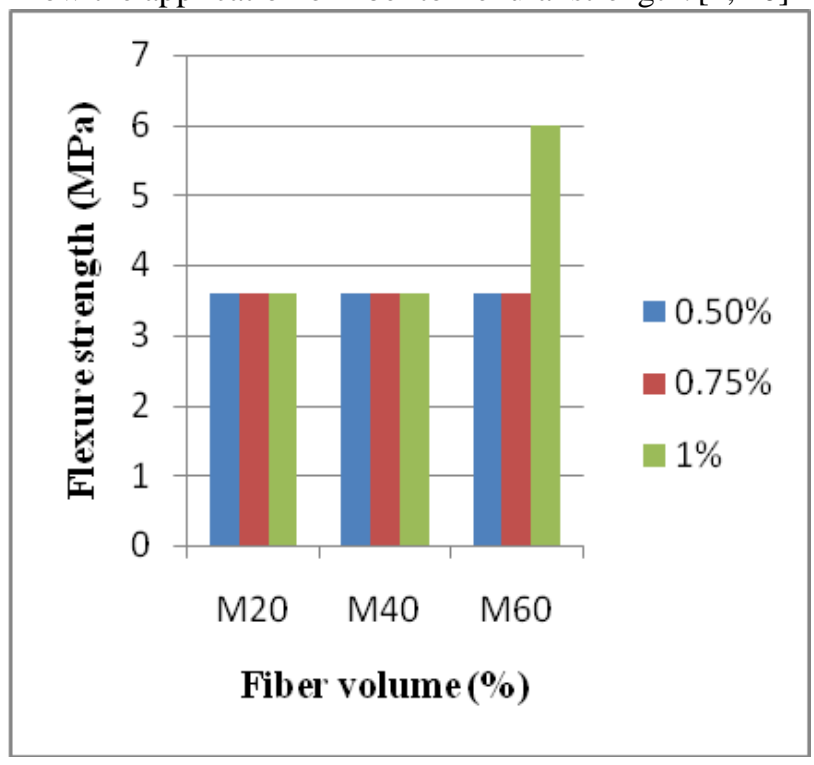

(a)Flexure strength Vs fiber volume for S1

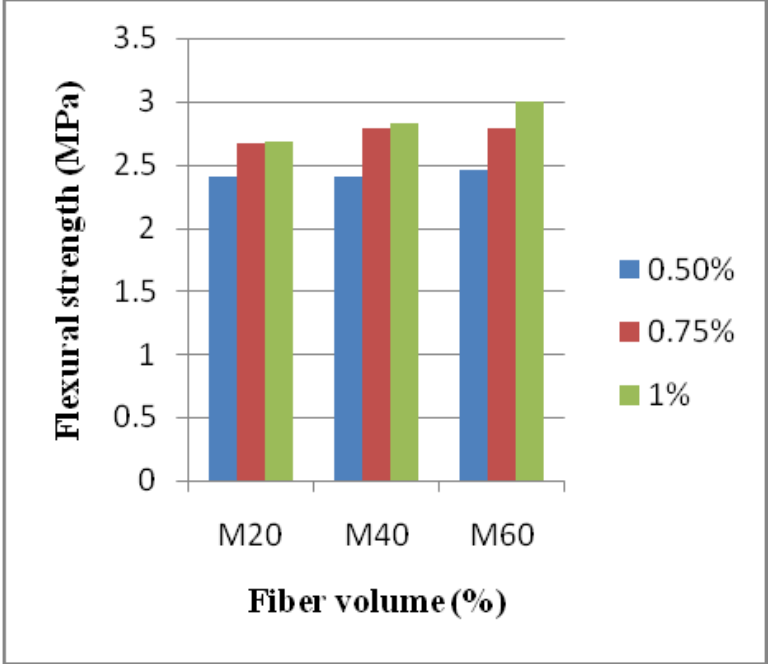

(b)Flexure strength Vs fiber volume for S2

Fig.8. Comparison of Flexure strength of different grades of concrete with varying fiber volume $[(a)$ and

(b)]

\section{Stiffness}

Stiffness is the material ability to withstand deformation. Since fibers were added to increase ductility of concrete it was necessary to concentrate over stiffness property of beam under applied load. The fig. 9 and 10 illustrates the stiffness of FRC beam with different dosage of fiber and also provides comparison of effect of fiber on different grades of concrete to increase stiffness property. From the obtained test results the stiffness of different beam specimens were calculated. Further comparisons were made to know what is effect of polypropylene fiber in increasing the stiffness of material. $[4,11]$

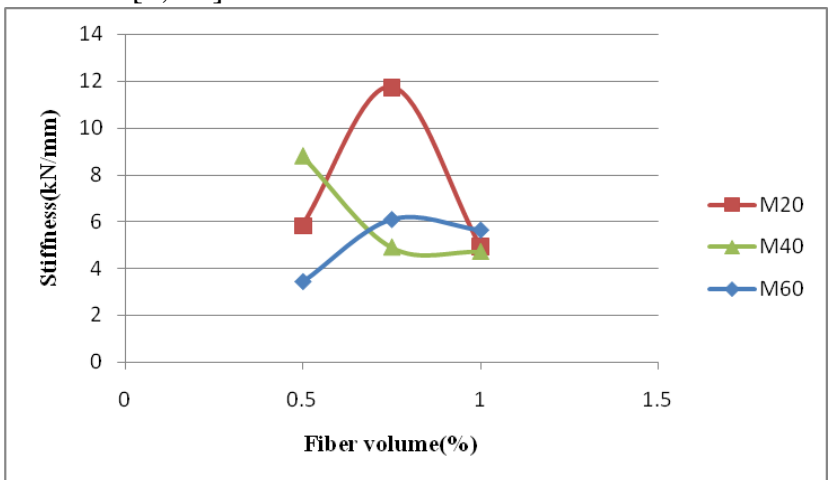

Fig.9. Stiffness Vs fiber volume for S1

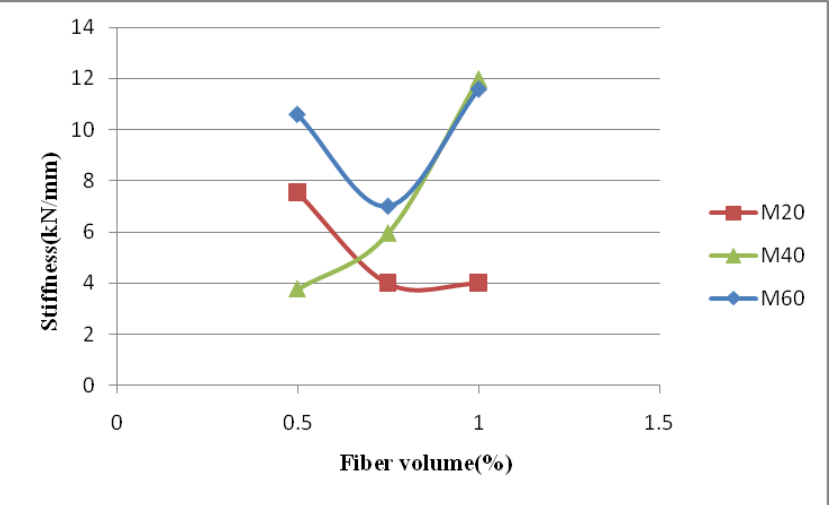

Fig.10. Stiffness Vs fiber volume for S2 


\section{D.Critical stress intensity factor}

Critical stress intensity factor was also called as fracture toughness. It was nothing but the point at which cracks propagate rapidly. The fracture toughness of different grades of concrete for both specimens were calculated using following formula [12]

$\mathrm{KIC}=\sigma \mathrm{N} \sqrt{ } \mathrm{a} F(\alpha)$

Where,

$$
\begin{aligned}
& \sigma \mathrm{N}=\text { Normal stress } \\
& \mathrm{a}=\text { notch depth }+ \text { length of crack } \\
& \mathrm{F}(\alpha)=1.99-\alpha(1-\alpha)\left(2.15-3.93 * \alpha+2.70 * \alpha^{2}\right) /(1+2 \alpha)(1-\alpha)^{3 / 2}
\end{aligned}
$$

Table V Fracture toughness for $1^{\text {st }}$ specimen $(150 \times 100 \times 600 \mathrm{~mm})$

\begin{tabular}{|c|l|l|l|}
\hline \multirow{2}{*}{ S 1 } & \multicolumn{3}{|l|}{$\begin{array}{l}\text { Critical stress intensity (MPa } \sqrt{ } \text { mm) } \\
\text { for different volume of fiber (\%) }\end{array}$} \\
\hline $\begin{array}{l}\text { Grade of } \\
\text { concrete }\end{array}$ & $0.5 \%$ & $0.75 \%$ & $1 \%$ \\
\hline M20 & 18.67 & 14.98 & 14.98 \\
\hline M40 & 19.7 & 15.9 & 15.9 \\
\hline M60 & 16.2 & 12.5 & 12.6 \\
\hline
\end{tabular}

Critical stress intensity for $600 \mathrm{~mm}$ span specimen

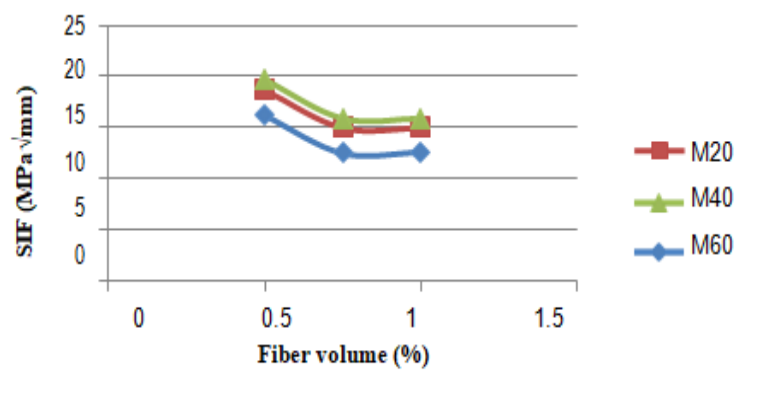

Fig.11.Critical SIF Vs fiber volume of $1^{\text {st }}$ Specimen (600mm span)

\begin{tabular}{|c|c|c|c|}
\hline S 2 & \multicolumn{3}{|c|}{$\begin{array}{l}\text { Critical stress intensity (MPa } \sqrt{ } \mathrm{mm}) \\
\text { for different volume of fiber }(\%)\end{array}$} \\
\hline Grade of concrete & $0.5 \%$ & $0.75 \%$ & $1 \%$ \\
\hline M20 & 31.15 & 27.98 & 27.95 \\
\hline M40 & 27.98 & 23.4 & 21.3 \\
\hline M60 & 23.4 & 23.4 & 29.3 \\
\hline
\end{tabular}

Table VI Fracture toughness for $2^{\text {nd }}$ specimen (150x200x1200mm)

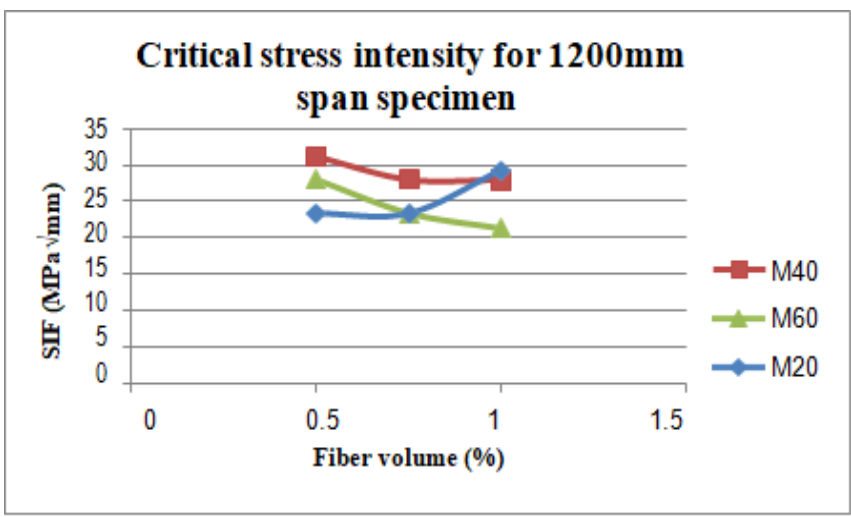

Fig.12.Critical SIF Vs fiber volume of $2^{\text {nd }}$ Specimen (1200mm span)

The critical SIF increases with respect to decrease in fiber volume (fig.11\& 12). But for concrete of grade M20 with specimen of span $1200 \mathrm{~mm}$, the SIF value found to be increased.

\section{E. Ultimate load and deflection}

The material once reaches its peak value the load on material suddenly falls down with increase in deflection value which was measured as ultimate load carried by the specimen and it is given in below table (table no. VII \& VIII).The ultimate load carried by both specimen for different grades of concrete were almost similar in comparison with literature study.[5]

Table VII Ultimate load and deflection for $1^{\text {st }}$ specimen $(600 \mathrm{~mm})$

\begin{tabular}{|c|l|l|l|l|l|l|}
\hline & \multicolumn{3}{|l|}{ Ultimate load (kN) } & \multicolumn{2}{l|}{ Deflection (mm) } \\
\hline $\begin{array}{c}\text { Grade of } \\
\text { concrete }\end{array}$ & $0.5 \%$ & $0.75 \%$ & $1 \%$ & $0.5 \%$ & $0.75 \%$ & $1 \%$ \\
\hline M20 & 0.6 & 0.3 & 0.27 & 1 & 1.2 & 1.23 \\
\hline M40 & 0.63 & 0.22 & 0.29 & 1.2 & 1.22 & 1 \\
\hline M60 & 0.7 & 0.26 & 0.29 & 1.53 & 1.1 & 2.3 \\
\hline
\end{tabular}

Ultimate load Vs deflection for $600 \mathrm{~mm}$ span specime

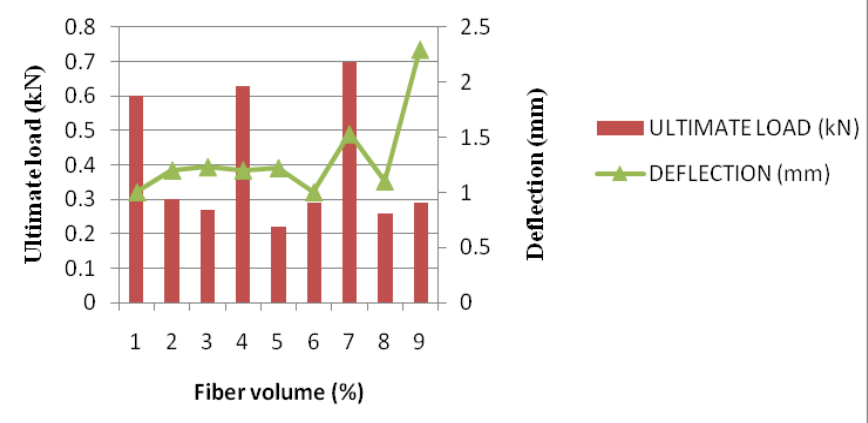

Fig.13.Ultimate load Vs deflection of $1^{\text {st }}$ Specimen (600mm span) 
Toughness Characterization of Fiber Reinforced Concrete Beam using Fracture Mechanics

Table VIII Ultimate load and deflection for $2^{\text {nd }}$ specimen (1200mm)

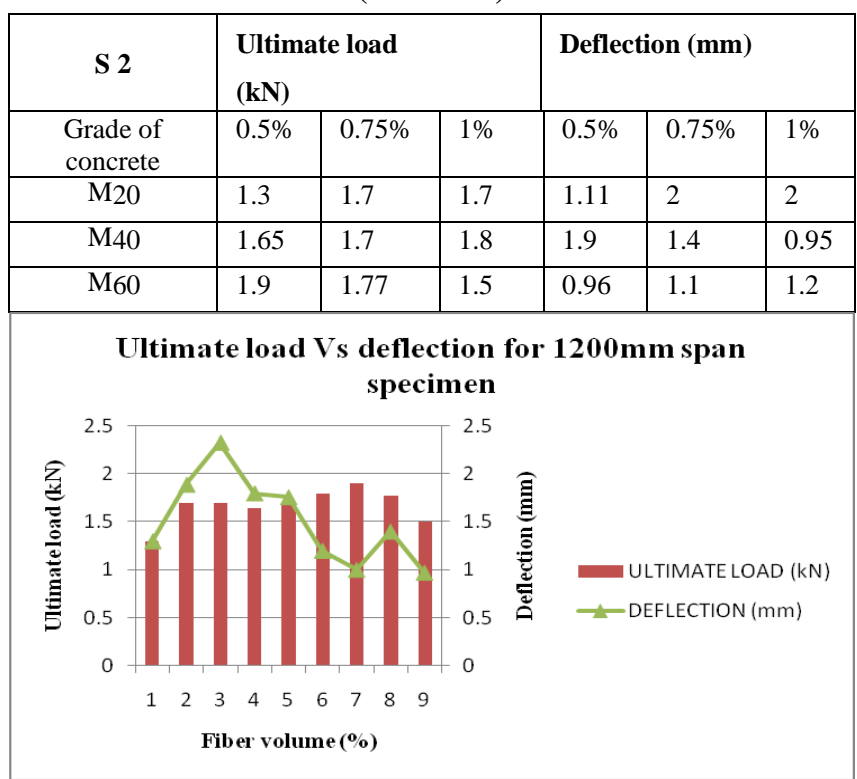

Fig.14.Ultimate load Vs deflection of $2^{\text {nd }}$ Specimen (1200mm span)

\section{F. Stress intensity factor}

The term stress intensity factor is used just to predict the stress near tip of the crack which was caused due to applied load. To calculate SIF of beam specimen following formula was used

$\mathrm{KIC}=(\mathrm{EC} \text { XGf })^{0.5}$

Where,

$\mathrm{E}_{\mathrm{C}}=$ Modulus of elasticity of concrete $(\mathrm{MPa})$

$\mathrm{G}_{\mathrm{f}}=$ Fracture energy $(\mathrm{N} / \mathrm{mm})$

Table IX Stress intensity factor for $1^{\text {st }}$ specimen $(600 \mathrm{~mm})$

\begin{tabular}{|c|l|l|l|}
\hline \multirow{2}{*}{ S 1 } & \multicolumn{3}{|c|}{ SIF for different fiber volume } \\
\hline Grade of concrete & $0.5 \%$ & $0.75 \%$ & $1 \%$ \\
\hline M20 & 95.69 & 115.5 & 115.5 \\
\hline M40 & 102.3 & 124.6 & 129.2 \\
\hline M60 & 103.2 & 127 & 167.4 \\
\hline
\end{tabular}

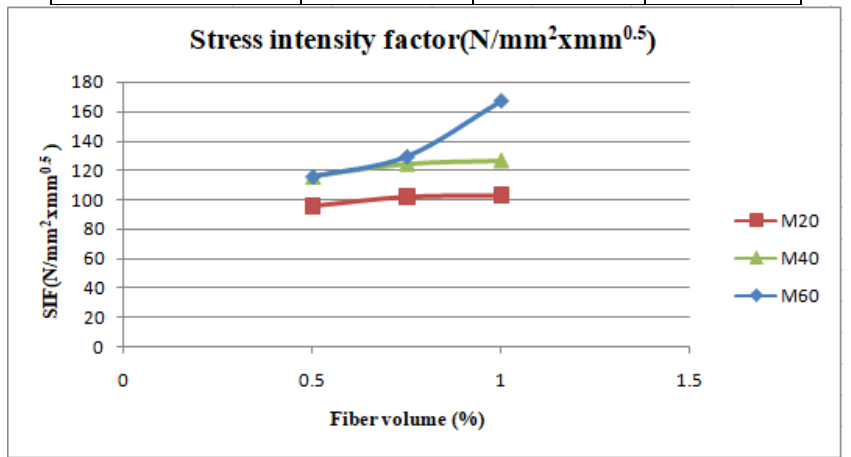

Fig.15.SIF Vs fiber volume of $1^{\text {st }}$ Specimen (600mm span)

Table X Stress intensity factor for $2^{\text {nd }}$ specimen $(1200 \mathrm{~mm})$

\begin{tabular}{|c|l|l|l|}
\hline \multirow{2}{*}{ S 2 } & \multicolumn{3}{|c|}{ SIF for different fiber volume } \\
\hline Grade of concrete & $0.5 \%$ & $0.75 \%$ & $1 \%$ \\
\hline M20 & 101.5 & 103.4 & 103.3 \\
\hline M40 & 111.4 & 124.6 & 127.7 \\
\hline M60 & 114.2 & 125.6 & 130.3 \\
\hline
\end{tabular}

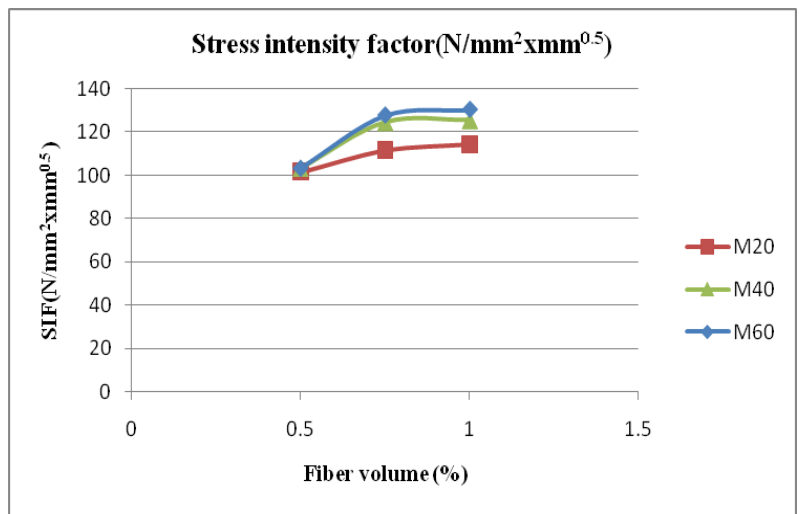

Fig.16.SIF Vs fiber volume of $2^{\text {nd }}$ specimen $(1200 \mathrm{~mm}$ span)

The stress intensity of both specimens shown in fig.15\&16. The SIF value for both specimen increases with increase in fiber volume and this value was found more in case of M20 grade for $600 \mathrm{~mm}$ span specimen and in case of $1200 \mathrm{~mm}$ span beam it almost remains constant for $0.75 \%$ and $1 \%$ volume fraction.

\section{GENERAL DISCUSSIONS}

The materials with two different sizes casted and tested under three point bending test and load-deflection of each specimens were obtained. Further using these test results required properties like fracture energy, flexural strength and stiffness were found and graphically represented with respect to fiber volume. These results show that $\mathrm{G}_{\mathrm{F}}$, flexural strength and stiffness increases with increase in fiber volume. It was observed that influence of fiber with volume of 0.75 to $1 \%$ affected more in case of medium and high strength concrete. And it was also observed that polypropylene fiber even though having lower elastic modulus gave better results.

\section{CONCLUSIONS}

Comparing the experimental results and discussions following conclusions were obtained.

- The fracture properties of normal, medium and high strength concrete increases with increase in fiber volume. There was no much influence of fiber with $0.5 \%$ dosage.

- Compared to normal strength concrete medium as well as high strength concrete with fiber volume of $0.75-1 \%$ showed increase in fracture properties.

- Polypropylene fiber with low modulus of elasticity and low aspect ratio provided higher capacity for deformation and improved fracture energy.

- The fracture properties like fracture energy, stress intensity factor, flexural strength, stiffness, critical SIF and CMOD of both specimens were found and compared with respect to fiber volume and grade of concrete. The graph plotted have represented that the fracture properties of both the specimens increases with increase in fiber volume and grade of concrete.

- By comparing stiffness results with different volume of fiber on both specimens, the effectiveness of polypropylene fiber with different dosage on high strength and medium strength concrete was more. For volume of $1 \%$ in both specimens there was much increase in load carrying capacity of beam.

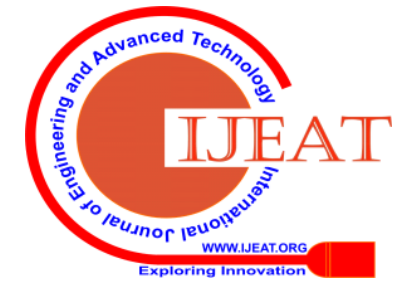


- The peak load, ultimate load, CMOD, length and width of crack for different dosage of polypropylene fiber in different grades of concrete was found almost similar with respect to literature study.

\section{ACKNOWLEDGMENT}

This research work was carried out at Jain College Engineering research lab. The authors would like to thank the management and staff for facility and technical support.

\section{REFERENCES}

1. Afroughsabet, V., \& Ozbakkaloglu, T. (2015). "Mechanical and durability properties of high-strength concrete containing steel and polypropylene fibers". Construction and building materials, 94, 73-82. https://doi.org/10.1016/j.conbuildmat.2015.06.05.

2. Barr, B., Asghari, A., \& Hughes, T. G. (1988). "Tensile strength and toughness of FRC materials". International Journal of Cement Composites and Lightweight Concrete, 10(2), 101-107. https://doi.org/10.1016/0262-5075(88)90036-X.

3. Bencardino, F., Rizzuti, L., Spadea, G., \& Swamy, R. N. (2010) "Experimental evaluation of fiber reinforced concrete fracture properties". Composites Part B: Engineering, 41(1), 17-24. www.elsevier.com/locate/compstruct.

4. Caggiano, A., Gambarelli, S., Martinelli, E., Nisticò, N., \& Pepe, M. (2016). "Experimental characterization of the post-cracking response in hybrid steel/polypropylene fiber-reinforced concrete". Construction and Building Materials, 125, 1035-1043. https://doi.org/10.1016/j.conbuildmat.2016.08.068

5. Chi, Y., Yu, M., Huang, L., \& Xu, L. (2017). "Finite element modeling of steel-polypropylene hybrid fiber reinforced concrete using modified concrete damaged plasticity". Engineering Structures, 148, 23-35. doi.org/10.1016/j.engstruct.2017.06.039.

6. Darwin, D., Barham, S., Kozul, R., \& Luan, S. (2001). "Fracture energy of high-strength concrete". American Concrete Institute. 98(5):410-417. http://www.reaearchgate.net.

7. Hillerborg, A. (1985). "The theoretical basis of a method to determine the fracture energyG F of concrete". Materials and structures, 18(4), 291-296. https://doi.org/10.1007/BF02472919.

8. Kazemi, M. T., Golsorkhtabar, H., Beygi, M. H. A., \& Gholamitabar, M. (2017). "Fracture properties of steel fiber reinforced high strength concrete using work of fracture and size effect methods". Construction and Building Materials, 142, 482-489. doi.org/10.1016/j.conbuildmat.2017.03.089.

9. Mastali, M., \& Dalvand, A. (2017). "Fresh and hardened properties of self-compacting concrete reinforced with hybrid recycled steel-Polypropylene fiber". Journal of Materials in Civil Engineering, 29(6),04017012. doi.org/10.1016/j.ijimpeng.2015.06.023.

10. Nia, A. A., Hedayatian, M., Nili, M., \& Sabet, V. A. (2012). "An experimental and numerical study on how steel and polypropylene fibers affect the impact resistance in fiber-reinforced concrete". International Journal of Impact Engineering, 46, 62-73. doi.org/10.1016/j.ijimpeng.2012.01.009.

11. Nili, M., Azarioon, A., Danesh, A., \& Deihimi, A. (2018) "Experimental study and modeling of fiber volume effects on frost resistance of fiber reinforced concrete". International Journal of CivilEngineering, 16(3),263-272.doi.org/10.1007/s40999-016-0122 -2 .

12. Reza, F. (2018). "Flexural Toughness Measurements on High-Strength Steel Fiber-Reinforced Concrete". doi.org/10.22606/mcse.2018.23001

13. Selvi, M. T., \& Thandavamoorthy, T. S. (2015). "Load-deflection characteristics of steel, polypropylene and hybrid fiber reinforced concrete beams". Archives of Civil Engineering,61(1), 59-72. doi.org/10.1515/ace-2015-0004.

14. Smarzewski, P. (2019). "Influence of basalt-polypropylene fibres on fracture properties of high performance concrete". Composite Structures, 209, 23-33.www.researchgate.net/.../330066763.

15.Zamri, M. N., Rahman, N. A., Jaini, Z. M., \& Bahador, N. S. (2017, November). "Effect of notch position on fracture energy for foamed concrete". In IOP Conference Series: Materials Science and Engineering, Vol. 271.researchgate.net.328396991.

\section{AUTHORS PROFILE}
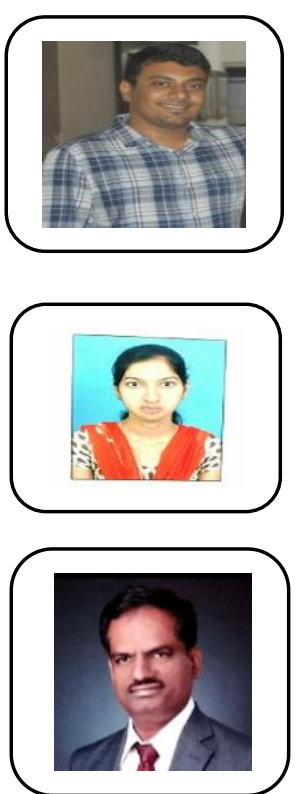

Kiran M. Malipatil, Working as Assistan Professor and pursuing his $\mathrm{PhD}$ in the Department of Civil Engineering, KLE DRMSSCET Belagavi, Karnataka, India. His research interests are Fracture Mechanics, Finite Element Method. He has published many papers in reputed Journals and Conferences.

Varunashree Meti, Completed Master of Technology (MTech.) in Structural engineering and bagged $5^{\text {th }}$ rank to VTU, Belagavi, Karnataka, India.

Dr S.V. Itti, Working as Professor in the Department of Civil Engineering, SGBIT, Belagavi, Karnataka. He was Principal of SGBIT, Belagavi. His research interests are Fracture Mechanics; Optimization Technique He has published many papers in reputed Journals and Conferences. 